\title{
Gamma-Aminobutyric Acid Production from a Novel Enterococcus avium JS-N6B4 Strain Isolated from Edible Insects
}

\author{
Min-Ho Jo ${ }^{1 \dagger}$, Seong-Jin Hong ${ }^{1 \dagger}$, Ha-Nul Lee ${ }^{1}$, Jung-Hyun Ju², Bo-Ram Park ${ }^{3}$, Jun-ho Lee ${ }^{4}$, Sun-Am Kim ${ }^{5}$, \\ Jong-Bang Eun ${ }^{1}$, Young-Jung Wee ${ }^{6 *}$, and Young-Min Kim ${ }^{1 *}$ \\ ${ }^{1}$ Department of Food Science Technology, Chonnam National University, Gwangju 61186, Republic of Korea \\ ${ }^{2}$ Microbial Biotechnology Research Center, Jeonbuk Branch Institute, Korea Research Institute of Bioscience and Biotechnology (KRIBB), \\ Jeonbuk, Jeongeup 56212, Republic of Korea \\ ${ }^{3}$ Department of Agro-food Resources National Academy of Agricultural Science, Rural Development Administration, Jeonju 54875, Republic \\ of Korea \\ ${ }^{4}$ Department of Biotechnology, Chonnam National University, Gwangju 61186, Republic of Korea \\ ${ }^{5}$ Jeonnam Bioindustry Foundation Bio Control Research Center, Gokseong 57509, Republic of Korea \\ ${ }^{6}$ Department of Food Science and Technology, Yeungnam University, Gyeongsan 38541, Republic of Korea
}

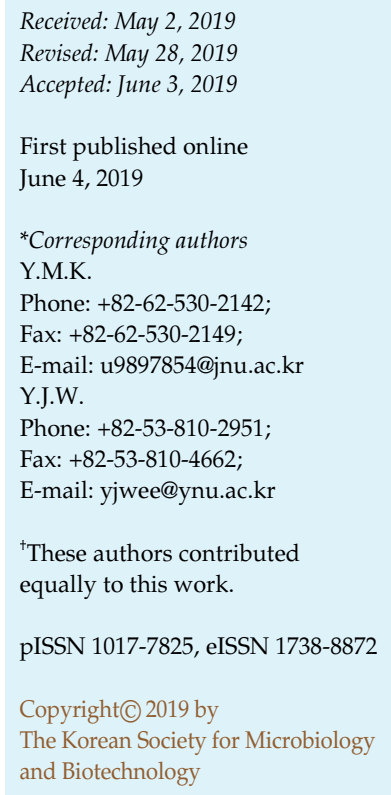

Gamma-aminobutyric acid (GABA)-producing strains were isolated from four edible insects and subjected to 16S rRNA sequence analysis. Among the four GABA-producing bacteria, Enterococcus avium JS-N6B4 exhibited the highest GABA-production, while cultivation temperature, initial $\mathrm{pH}$, aerobic condition, and mono-sodium glutamate (MSG) feeding were found to be the key factors affecting GABA production rate. The culture condition was optimized in terms of glucose, yeast extract, and MSG concentrations using response surface methodology (RSM). GABA production up to $16.64 \mathrm{~g} / 1$ was obtained under the conditions of $7 \mathrm{~g} / 1$ glucose, $45 \mathrm{~g} / 1$ yeast extract, and $62 \mathrm{~g} / 1$ MSG through the optimization of medium composition by RSM. Experimental GABA production was $13.68 \mathrm{~g} / \mathrm{l}$, which was close to the predicted value $(16.64 \mathrm{~g} / \mathrm{l})$ calculated from the analysis of variance, and 2.79-fold higher than the production achieved with basic medium. Therefore, GABA-producing strains may help improve the GABA production in edible insects, and provide a new approach to the use of edible insects as effective food biomaterials.

Keywords: Edible insects, gamma-aminobutyric acid, Enterococcus avium, mono-sodium glutamate, optimization

\section{Introduction}

Gamma-aminobutyric acid (GABA) is a four-carbon, non-protein derived amino acid widely expressed in bacteria, plants, and vertebrates. It is one of the major inhibitory neurotransmitters in the mammalian central nervous system and is extensively found in animals, plants, and microorganisms $[1,2]$. GABA is primarily biosynthesized by glutamic acid decarboxylase (GAD; E.C. 4.1.1.15), a pyridoxal-5'-phosphate-dependent enzyme that catalyzes the irreversible $\alpha$-decarboxylation of L-glutamic acid to
GABA through the incorporation of hydrogen ions [3, 4]. GABA exhibits several physiological functions such as antihypertensive, diuretic, and anti-diabetic effects in humans. In addition, GABA exerts tranquilizing effects, particularly related to depression, sleeplessness, and neurological disorders such as Parkinson's disease, Huntington's chorea, and Alzheimer's disease [3-6]. GABA is one of the many signaling molecules in the brain and is an important modulator of the immune function [7]. As a result, studies have been directed toward the development of functional foods containing GABA, including cereals, 
sourdough, breads, cheese, fermented sausages, teas, vegetables, legumes, dairy soy products, alcohol beverages, and traditional Asian fermented foods [8].

Edible insects have received considerable attention as effective protein substitutes; however, there are several obstacles for their industrial use. First, people generally have a revulsion about insects and relate consumption with starvation and the only means of survival in developing countries. These misunderstandings are caused by the aversion of Western society to insect consumption [9]. Therefore, it is necessary to increase awareness about edible insects, owing to their having high nutritional value and positive impact on the environment, which may eventually change the perception about insect consumption. Second, large-scale insect breeding systems are warranted to increase the commercial availability of edible insects. Current production systems are very expensive, and conventional studies have shown that the cost of producing mealworm is 4.8 times higher than that of producing regular chicken feed. Labor and housing costs, especially for large-scale insect feed production, are much higher than those for chicken feed [10]. Therefore, it is necessary to increase the awareness about edible insects as an alternative to animal protein by reducing the cost of production in large-scale production systems. This may demand the development of automated systems for breeding and processing. It is necessary to create competitive market prices by continuously producing massive quantities of excellent quality insects [10]. The aim of this study was to increase the industrial usage of edible insects by producing high value-added products, achieved by providing functionality to insect proteins prior to the development of large-scale production systems. In the development of edible insects as protein substitutes, GABA may serve as an attractive biomaterial and impart higher value to the final product.

Several studies have evaluated microorganisms that produce GABA, particularly Korean fermented foods such as kimchi [11, 12], makgeolli [13], fish products [14], cheese [15-17], and sourdough [18] as well as Chinese fermented foods such as paocai [19]. Studies have also been conducted to maximize GABA production from isolated strains, and using recombinant enzymes. However, no report has described the use of strains isolated from edible insects except for the isolation of microbes from honeybees [3]. Domestic edible insects recognized as food materials in South Korea include Bombyx mori larvae infected with Beauveria bassiana (Bals.) Vuill., Bombyx mori larvae, mealworm (Tenebrio molitor larvae), Oxya japonica Thunberg, Protaetia brevitarsis, Allomyrina dichotoma, and the two-spotted cricket (Gryllus bimaculatus). It is essential to impart high value to edible insects to increase their value as protein substitutes with the methods such as GABA fortification.

In this study, GABA-producing bacteria were isolated from four edible insects, and Enterocuccus avium JS-N6B4 was found as the best GABA producer. The optimum culture conditions for E. avium JS-N6B4 growth were investigated using response surface methodology (RSM).

\section{Materials and Methods}

\section{Materials}

Mono-sodium glutamate (MSG) and GABA at $\geq 96 \%$ purity were purchased from Daejung (Korea) and Alfa-Aesar (Thermo Fisher Scientific, USA). Four GABA-producing bacteria were isolated from edible insects such as G. bimaculatus, T. molitor larvae, $P$. brevitarsis larvae, and A. dichotoma larvae provided by the Bio Control Research Center (Korea). All other chemicals used were of reagent grade.

\section{Isolation and 16S rRNA Gene Sequencing of the GABA- Producing Strains from the Edible Insects}

The ground insects were subjected to extraction with sterilized water at $25^{\circ} \mathrm{C}$ for $1 \mathrm{~h}$ and incubated on solid MRS medium (Difco, USA) at $37^{\circ} \mathrm{C}$ for $24 \mathrm{~h}$. To isolate GABA-producing strains, the selected colonies were cultivated in modified MRS broth containing $1 \%(\mathrm{w} / \mathrm{v})$ MSG at $37^{\circ} \mathrm{C}$ for $72 \mathrm{~h}$ [11]. Extraction of genomic DNA of the four GABA-producing strains was carried out using Chelex 100 beads (Bio-Rad Laboratories, USA). The 16S rRNA gene was subjected to polymerase chain reaction (PCR) based amplification using the chromosomal DNA and universal bacterial primer pair 27F (5'-AGAGTTTGATCCTGGCTCAG-3') and 1492R (5'-GGCTACCTTGTTACGACTT-3'). The purified PCR products were sequenced by SolGent (Korea). Multi-alignment of related strains was performed using Clustal W [20].

\section{Qualitative and Quantitative Analyses of GABA Production}

Qualitative analysis of GABA production was carried out with thin-layer chromatography (TLC) [21]. Culture supernatants after centrifugation at $11,463 \times g$ for 10 min were immediately spotted on TLC silica gel plates (Merck, USA) and developed twice using a solvent mixture comprising $n$-butanol/acetic acid/water (5:3:2, $\mathrm{v} / \mathrm{v} / \mathrm{v})$ followed by the addition of $0.2 \%(\mathrm{w} / \mathrm{v})$ ninhydrin reagent in ethanol for visualization [22].

Quantitative analysis of GABA was carried out as per the method described by Rossetti and Lombard with some modifications [23]. In brief, $10 \mu \mathrm{l}$ of culture supernatants were dissolved in $20 \mu \mathrm{l}$ of ethanol/water/triethylamine (TEA) (2:2:1, v/v/v) and evaporated to dryness under vacuum. To form phenyl isothiocyanate (PITC) derivatives, a PITC derivatization reagent $(50 \mu \mathrm{l})$ (ethanol/water/ TEA/phenyl-isothiocyanate $[7: 1: 1: 1, \mathrm{v} / \mathrm{v} / \mathrm{v} / \mathrm{v}]$ ) was added to 
each sample and allowed to react for $40 \mathrm{~min}$ at $25^{\circ} \mathrm{C}$. The excess of reagent was removed under vacuum for $20 \mathrm{~min}$, and the dried samples were dissolved in $600 \mu \mathrm{l}$ of solvent A (1.4 mM sodium acetate, $0.1 \%$ TEA, $6 \%$ acetonitrile, $\mathrm{pH} 5.5)$. Diluted samples were filtered through a $0.20-\mu \mathrm{m}$ syringe filter (Advantech Toyo Kaisha, Japan), and the derivatized samples were injected onto a highperformance liquid chromatography column (HPLC, Shimadzu, Japan) using an HPLC system equipped with Agilent ZORBAX 300SB-C ${ }_{18}(5 \mu \mathrm{m}, 4.6 \times 150 \mathrm{~mm}$, Agilent Technologies, Palo Alto, CA, USA), pumps A and B (LC-20AD, Shimadzu, Kyoto, Japan), and a UV-VIS detector (SPD-20A, Shimadzu, Japan). The column was eluted for $40 \mathrm{~min}$ with a linear gradient of $0-100 \%$ solvent $B$ $\left(60 \%\right.$ acetonitrile) at a flow rate of $0.5 \mathrm{ml} / \mathrm{min}$ at $46^{\circ} \mathrm{C}$ for $40 \mathrm{~min}$. Sample was injected at a volume of $5 \mu \mathrm{l}$ and monitored at a wavelength of $254 \mathrm{~nm}$. The same method was applied to GABA standard. The PITC derivative of GABA was eluted at $10.6 \mathrm{~min}$. A calibration curve was produced by applying the same procedure to eight standard solutions of GABA $(0.156,0.313,0.625,1.25,2.5$, $5.0,10.0$, and $20.0 \mathrm{~g} / \mathrm{l})$.

\section{GABA Production}

Each strain was seed-cultured at $37^{\circ} \mathrm{C}$ in $10 \mathrm{ml}$ of modified MRS broth containing $1 \%(\mathrm{w} / \mathrm{v})$ MSG. Cultures were incubated under shaking conditions until the optical density reached 1.0 at $600 \mathrm{~nm}$ wavelength. Each strain was sub-cultured into $20 \mathrm{ml}$ modified MRS broth and incubated at $37^{\circ} \mathrm{C}$ for $96 \mathrm{~h}$. The simplified media containing $10 \mathrm{~g} / \mathrm{l}$ of a carbon source (glucose, fructose, galactose, xylose, maltose, sucrose, lactose, or mannitol), $10 \mathrm{~g} / 1$ yeast extract, $10 \mathrm{~g} / 1 \mathrm{MSG}$, and $1 \mathrm{~g} / 1$ di-potassium phosphate $\left(\mathrm{K}_{2} \mathrm{HPO}_{4}\right)$ were prepared to investigate the influence of carbon source on levels of GABA produced by each strain. Each isolated strain was seedcultured at $37^{\circ} \mathrm{C}$ for $18 \mathrm{~h}$ in $10 \mathrm{ml}$ of modified MRS broth starting from $1 \%(\mathrm{v} / \mathrm{v})$ inoculum. Strains were then inoculated into $20 \mathrm{ml}$ simplified media supplemented with various carbon sources and incubated at $37^{\circ} \mathrm{C}$ for $96 \mathrm{~h}$. Supernatants were harvested for the analysis of GABA production.

After the selection of the carbon source that allowed maximum GABA production, the simplified media containing $10 \mathrm{~g} / \mathrm{l}$ carbon source with the highest GABA production, $10 \mathrm{~g} / 1$ nitrogen source (yeast extract, beef extract, malt extract, peptone, tryptone, soytone, proteose peptone No. 3, casein, urea, or ammonium chloride), $10 \mathrm{~g} / 1 \mathrm{MSG}$, and $1 \mathrm{~g} / 1 \mathrm{~K}_{2} \mathrm{HPO}_{4}$ were prepared to investigate the effect of nitrogen source on GABA production of each strain. Each strain was seed-cultured at $37^{\circ} \mathrm{C}$ for $18 \mathrm{~h}$ in $10 \mathrm{ml}$ of medium. Strains were then cultured in $20 \mathrm{ml}$ simplified media supplemented with various nitrogen sources at $37^{\circ} \mathrm{C}$ for $96 \mathrm{~h}$, and the culture supernatants were harvested for the analysis of GABA production.

\section{Culture Conditions for GABA Production}

Among the isolated GABA-producing strains, E. avium JS-N6B4 isolated from $A$. dichotoma larvae showed maximum GABA production. Further characterization of culture conditions was carried out for this strain. Simplified media (10 g/l carbon source [glucose, fructose, galactose, xylose, maltose, sucrose, lactose, or mannitol] $10 \mathrm{~g} / 1$ yeast extract, $10 \mathrm{~g} / 1 \mathrm{MSG}$, and $1 \mathrm{~g} / 1 \mathrm{~K}_{2} \mathrm{HPO}_{4}$ ) were prepared to investigate the effect of carbon source. E. avium JS-N6B4 was seed-cultured at $37^{\circ} \mathrm{C}$ for $18 \mathrm{~h}$ in $10 \mathrm{ml}$ of modified MRS broth containing $1 \%(\mathrm{w} / \mathrm{v})$ MSG. The strain was then subcultured in $20 \mathrm{ml}$ of each basic medium containing various carbon sources, and incubated at $37^{\circ} \mathrm{C}$ for $96 \mathrm{~h}$. Supernatants were harvested for the analysis of GABA production.

After evaluation of the carbon source that yielded the highest GABA level, the simplified media $(10 \mathrm{~g} / 1$ carbon source with the highest GABA production, $10 \mathrm{~g} / 1$ various nitrogen sources, $10 \mathrm{~g} / 1$ MSG, and $1 \mathrm{~g} / 1 \mathrm{~K}_{2} \mathrm{HPO}_{4}$ ) were prepared to investigate the effect of nitrogen source on GABA production. The strain was seedcultured at $37^{\circ} \mathrm{C}$ for $18 \mathrm{~h}$ in $10 \mathrm{ml}$ of medium and cultured in $20 \mathrm{ml}$ of each basic medium containing various nitrogen sources at $37^{\circ} \mathrm{C}$ for $96 \mathrm{~h}$. The supernatants were harvested for the analyses of GABA production.

The effect of incubation temperature on GABA production by E. avium JS-N6B4 was investigated. The strain was seed-cultured at $37^{\circ} \mathrm{C}$ in $10 \mathrm{ml}$ modified MRS broth containing $1 \%(\mathrm{w} / \mathrm{v}$ ) MSG. These cultures were used to inoculate $20 \mathrm{ml}$ cultures of basic medium (10 g/l glucose, $10 \mathrm{~g} / 1$ yeast extract, $10 \mathrm{~g} / 1 \mathrm{MSG}$, and $1 \mathrm{~g} / 1 \mathrm{~K}_{2} \mathrm{HPO}_{4}$ ) and incubated under shaking conditions at $30^{\circ} \mathrm{C}$, $33^{\circ} \mathrm{C}, 37^{\circ} \mathrm{C}, 41^{\circ} \mathrm{C}$, and $45^{\circ} \mathrm{C}$ for $96 \mathrm{~h}$.

The effect of initial $\mathrm{pH}$ of the medium on GABA production by E. avium JS-N6B4 was evaluated. The strain was seed-cultured at $37^{\circ} \mathrm{C}$ in multiple $10-\mathrm{ml}$ tubes of modified MRS broth containing $1 \%(\mathrm{w} / \mathrm{v})$ MSG. Seed cultures were used to inoculate $20 \mathrm{ml}$ cultures containing basic medium $(10 \mathrm{~g} / 1$ glucose, $10 \mathrm{~g} / 1$ yeast extract, $10 \mathrm{~g} / 1 \mathrm{MSG}$, and $1 \mathrm{~g} / 1 \mathrm{~K}_{2} \mathrm{HPO}_{4}$ ) adjusted to an initial $\mathrm{pH}$ of $4.0,4.5,5.0,5.5,6.0,6.5,7.0,7.5$, and 8.0 with $2 \mathrm{M}$ hydrochloric acid or $1 \mathrm{M}$ sodium hydroxide. These cultures were incubated at $37^{\circ} \mathrm{C}$ under shaking conditions for $96 \mathrm{~h}$.

The effects of aerobic and anaerobic conditions on GABA production were investigated. For aerobic conditions, the strain was seed-cultured in two flasks of $20 \mathrm{ml}$ modified MRS broth and cultured at $37^{\circ} \mathrm{C}$ for $18 \mathrm{~h}$ at $180 \mathrm{rpm}$. One of the flasks was blocked with a cotton plug, and the other was blocked with foil. Each seed culture was used to inoculate $100 \mathrm{ml}$ of basic medium, and these cultures were then incubated with shaking at $180 \mathrm{rpm}$, at $37^{\circ} \mathrm{C}$ for $96 \mathrm{~h}$. For anaerobic conditions, the strain was seed-cultured in $20 \mathrm{ml}$ modified MRS broth, and topped with liquid paraffin. These cultures were covered with foil and cultured at $37^{\circ} \mathrm{C}$ for $18 \mathrm{~h}$ without shaking. The strain was also inoculated into $100 \mathrm{ml}$ basic medium with liquid paraffin, and $100 \mathrm{ml}$ basic medium without liquid paraffin, and incubated at $37^{\circ} \mathrm{C}$ for $96 \mathrm{~h}$ without shaking.

The effect of MSG on GABA production was evaluated. The strain was inoculated in $20 \mathrm{ml}$ of modified MRS broth and cultured at $37^{\circ} \mathrm{C}$ for $18 \mathrm{~h}$. A $100-\mathrm{ml}$ flask of basic medium containing an initial MSG concentration of $10 \mathrm{~g} / 1$ was inoculated and incubated for $96 \mathrm{~h}$. During cultivation, $10 \mathrm{~g} / \mathrm{l}$ of MSG was added every $24 \mathrm{~h}$ to achieve a final MSG concentration of $40 \mathrm{~g} / \mathrm{l}$. Another 100-ml flask initially containing $40 \mathrm{~g} / 1$ MSG was 
inoculated and cultured at $37^{\circ} \mathrm{C}$ for $96 \mathrm{~h}$ without any further addition of MSG. A third 100-ml flask of basic medium initially containing $40 \mathrm{~g} / 1 \mathrm{MSG}$ was inoculated and cultured at $37^{\circ} \mathrm{C}$ for $96 \mathrm{~h}$. An additional $20 \mathrm{~g} / \mathrm{l}$ of MSG was added every $24 \mathrm{~h}$ to achieve a final MSG concentration of $100 \mathrm{~g} / \mathrm{l}$. A fourth flask of basic medium containing an initial MSG concentration of $100 \mathrm{~g} / 1$ was inoculated and cultured at $37^{\circ} \mathrm{C}$ for $96 \mathrm{~h}$ without further additions of MSG.

\section{Optimization for GABA Production with RSM}

Based on the results obtained from the preliminary screening for GABA production, a central composite design (CCD) experiment was performed with concentrations in the vicinity of optimum range to determine the precise optimum concentrations of glucose, yeast extract, and MSG. The CCD matrix was generated using Design-Expert software (Stat-Ease Inc., USA). Each factor in the design was studied at five different levels $(-1.682,-1,0,+1$, and +1.682$)$. The design matrix corresponding to the CCD is shown in Table 1.

Analysis of variance (ANOVA) was used with the response function, and the relationships and interactions between variables

Table 1. The central composite design matrix of independent variables.

\begin{tabular}{|c|c|c|c|c|c|}
\hline \multirow[t]{2}{*}{ Runs } & \multirow{2}{*}{$\begin{array}{r}\text { Glucose } \\
(A, \mathrm{~g} / \mathrm{l})\end{array}$} & \multirow{2}{*}{$\begin{array}{c}\text { Yeast } \\
\text { extract } \\
(B, \mathrm{~g} / \mathrm{l})\end{array}$} & \multirow{2}{*}{$\begin{array}{c}\text { MSG } \\
(C, \%-\mathrm{w} / \mathrm{v})-\end{array}$} & \multicolumn{2}{|c|}{$\begin{array}{c}\text { GABA } \\
\text { production }(\mathrm{g} / \mathrm{l})\end{array}$} \\
\hline & & & & Experimental & Predicted \\
\hline 1 & 2 & 15 & 2 & 3.53 & 2.51 \\
\hline 2 & 7 & 15 & 2 & 10.47 & 9.72 \\
\hline 3 & 2 & 45 & 2 & 8.97 & 7.25 \\
\hline 4 & 7 & 45 & 2 & 11.44 & 11.93 \\
\hline 5 & 2 & 15 & 7 & 1.64 & 0.31 \\
\hline 6 & 7 & 15 & 7 & 10.08 & 10.95 \\
\hline 7 & 2 & 45 & 7 & 8.45 & 8.36 \\
\hline 8 & 7 & 45 & 7 & 16.29 & 16.48 \\
\hline 9 & 0.30 & 30 & 4.5 & 2.52 & 4.60 \\
\hline 10 & 8.70 & 30 & 4.5 & 18.39 & 17.50 \\
\hline 11 & 4.5 & 4.77 & 4.5 & 4.18 & 5.10 \\
\hline 12 & 4.5 & 55.23 & 4.5 & 13.47 & 13.74 \\
\hline 13 & 4.5 & 30 & 0.30 & 2.70 & 4.08 \\
\hline 14 & 4.5 & 30 & 8.70 & 6.24 & 6.05 \\
\hline 15 & 4.5 & 30 & 4.5 & 8.83 & 9.75 \\
\hline 16 & 4.5 & 30 & 4.5 & 9.79 & 9.75 \\
\hline 17 & 4.5 & 30 & 4.5 & 9.95 & 9.75 \\
\hline 18 & 4.5 & 30 & 4.5 & 10.93 & 9.75 \\
\hline 19 & 4.5 & 30 & 4.5 & 9.47 & 9.75 \\
\hline 20 & 4.5 & 30 & 4.5 & 9.73 & 9.75 \\
\hline
\end{tabular}

Variable values are correlated with experimental and predicted GABA concentrations produced by E. avium JS-N6B4. were determined using the following second-order polynomial equation:

$$
y=\beta_{0}+\sum \beta_{i j} x_{i} x_{j}+\sum \beta_{i i} x_{i}^{2}
$$

where $y$ is the predicted response, $\beta_{0}$ is the offset term, $\beta_{i}$ is the linear effect, $\beta_{i j}$ is the quadratic effect when $i=j$, and the interaction effect when $i<j, \beta_{i j}$ is the squared term, and $x_{i}$ is the $i$ th independent variable. The data were statistically analyzed with Design-Expert 7.1 (Stat-Ease Inc.), and response surface and contour plots were constructed to evaluate interaction effects of the parameters as well as the optimum value of each variable. A set of optimized experimental conditions was tested to evaluate GABA production and confirm the validity of RSM results. Fermentation was carried out in a 100-ml flask containing the optimized medium at $37^{\circ} \mathrm{C}$ for $96 \mathrm{~h}$. Samples were aseptically obtained and analyzed for cell growth (optical density ${ }_{600 \mathrm{~mm}}$ ), $\mathrm{pH}$, and GABA production $(\mathrm{g} / \mathrm{l})$.

\section{Statistical Analysis}

All experiments were conducted in duplicate. The data were analyzed for statistical significance with ANOVA followed by Duncan's multiple-range test using SPSS version 18.0 (USA). The level of significance was set at $p<0.05$.

\section{Results and Discussion}

\section{Phylogenetic Identification of GABA-Producing Strains from Edible Insects}

We investigated the GABA production ability of 87 isolates from four edible insects. Most strains showed a very low level of GABA production. Among 87 isolates, four bacterial strains were subjected to $16 \mathrm{~S}$ rRNA sequencing. The isolated strains had the lowest sequence similarity value based on the 16S rRNA gene sequence, suggesting that these may be classified as E. avium or Proteus sp. As shown in Fig. 1, the strain isolated from G. bimaculatus was identified as Proteus sp. L-G7, while the strains isolated from T. molitor larvae, $P$. brevitarsis larvae, and A. dichotoma larvae were identified and designated as E. avium No-22-1, Enterococcus avium $\mathrm{HJ}-\mathrm{N} 6$, and Enterococcus avium JS-N6B4, respectively. Most GABA-producing microbes have been isolated from traditional fermented foods such as kimchi [11, 12], makgeolli [13], fish products [14], cheese [15-17], sourdough [18], and paocai [19]. These sources generally provide an acidic environment and contain high levels of glutamate, a GABA precursor. The environmental conditions that the potential sources provide are, therefore, important in designing screen methods to isolate GABA-producing microbial strains [24]. Although several microbes are capable of producing GABA, the most notable sources are lactic 


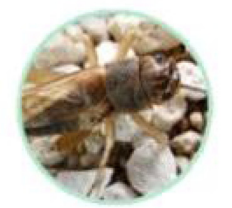

(two-sptted cricket,
Gryllus bimaculatus)

Proteus sp. L-G7

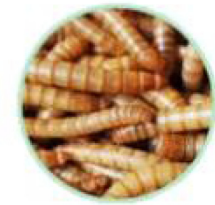

(mealworm, Tenebrio molitor L.)

\section{Enterococcus avium No-22-1}

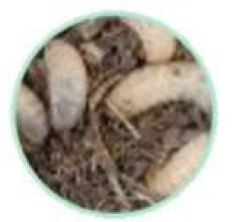

(Protaetia brevitarsis)

\section{Enterococcus avium HJ-N6}

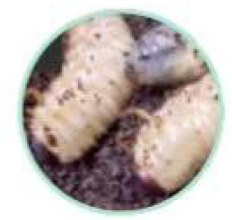

\section{(Allomyrina dichotoma)}

\section{Enterococcus avium JS-N6B4}

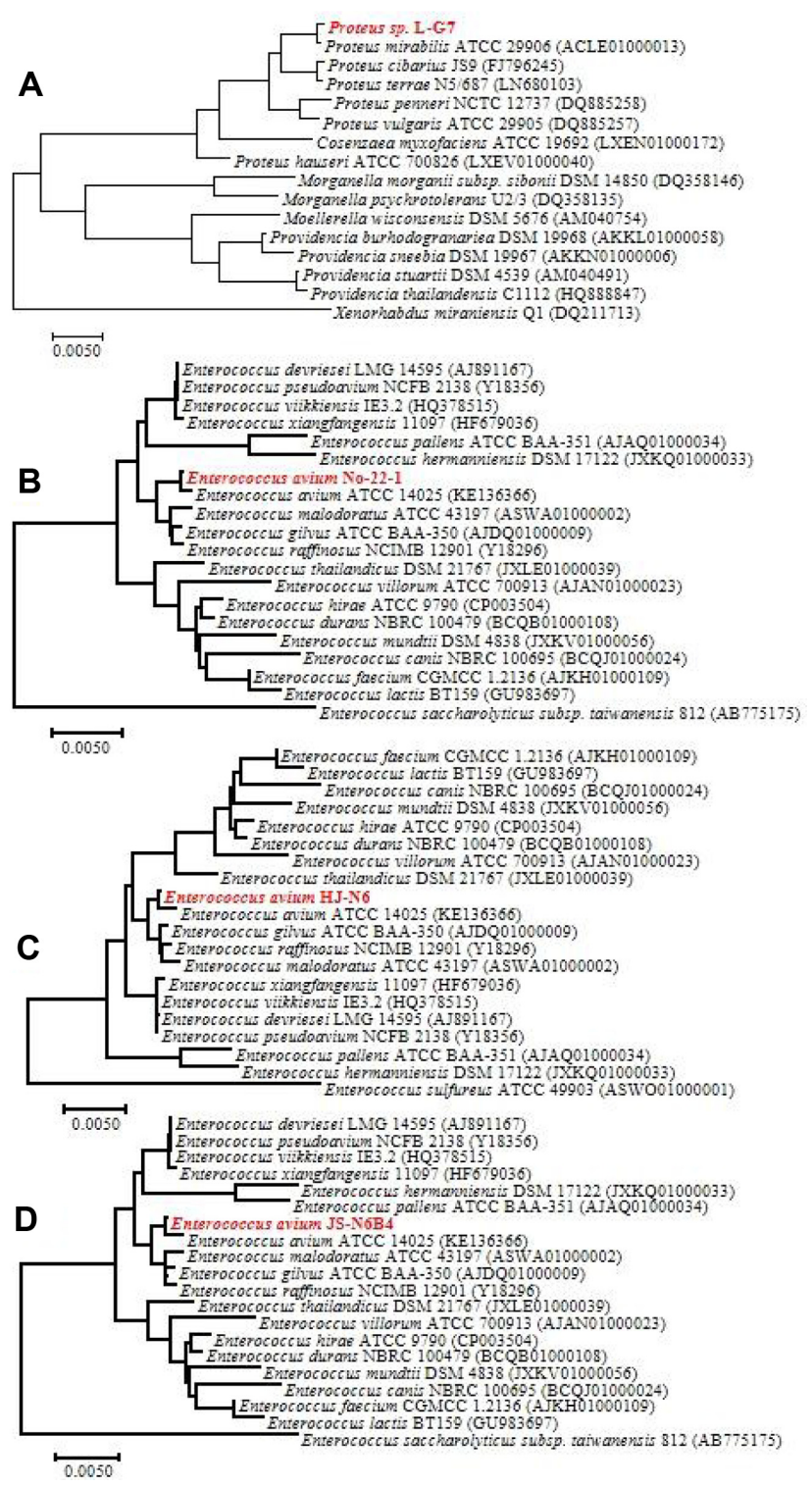

Fig. 1. Neighbor-joining phylogenetic tress based on the $16 \mathrm{~S}$ rRNA sequence analysis of GABA-producing strains isolated from edible insects and other related taxa.

(A) Proteus sp. L-G7 isolated from two-spotted cricket, (B) E. avium HJ-N6 isolated from P. brevitarsis larvae, (C) E. avium No-22-1 isolated from mealworm, and (D) E. avium JS-N6B4 isolated from A. dichotoma larvae.

acid bacteria (LAB) such as Lactobacillus or Leuconostoc. The environmental conditions with high concentrations of glutamate and acidic $\mathrm{pH}$ may facilitate the production of GABA [25].

GABA production by microbes in edible insects may be facilitated in the environment naturally formed by glutamate contained in the feed ingredients. Although many GABAproducing strains have been identified from various fermented foods, four strains with GABA-producing ability were successfully isolated from edible insects. To the best of our knowledge, this is the first report on GABAproducing bacteria isolated from edible insects. The identification of microbial sources of GABA may expand the applications and flexibility of edible insects [24].

\section{GABA Production by GABA-Producing Strains}

The GABA production from each isolated strain was compared using MRS broth containing 1\% (w/v) MSG 
A

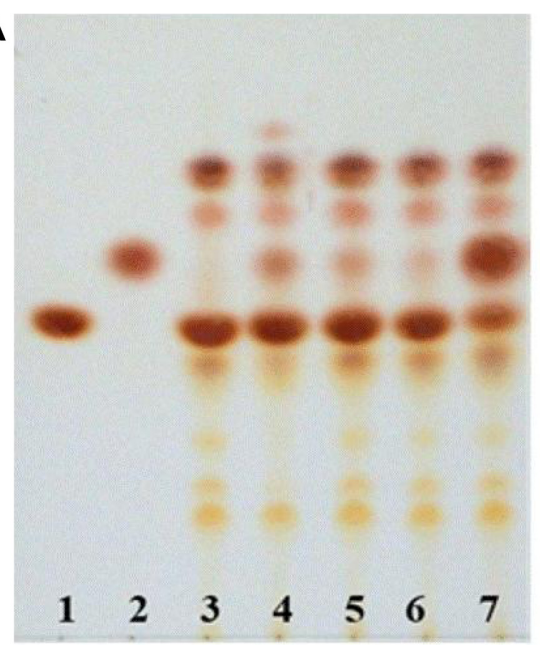

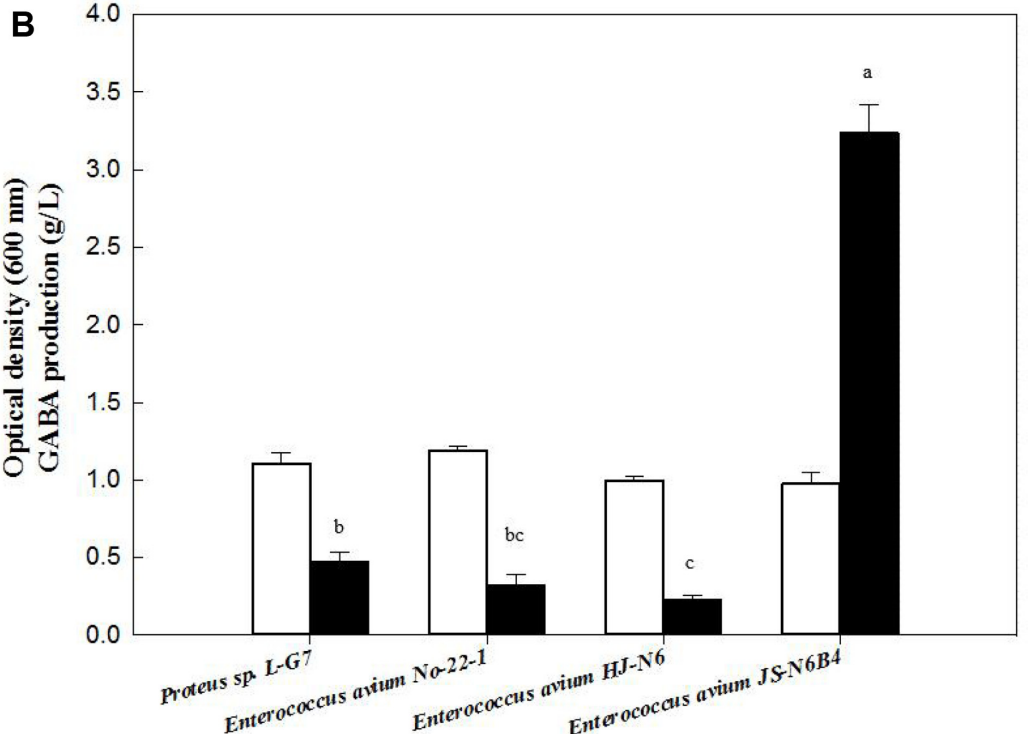

Fig. 2. Comparison of GABA production between four isolates from edible insects.

(A) Qualitative analysis of GABA from four isolates using thin-layer chromatography (TLC). Lane 1, $10 \mathrm{~g} / 1 \mathrm{MSG}$ standard; lane 2, $1.25 \mathrm{~g} / 1 \mathrm{GABA}$ standard; lane 3, MRS medium containing 1\% (w/v) MSG (control); lane 4, GABA production with Proteus sp. L-G7; lane 5, GABA production with E. avium HJ-N6; lane 6, GABA production with E. avium No-22-1; lane 7, GABA production with E. avium JS-N6B4. (B) Growth and GABA production of GABA-producing strains isolated from edible insects. ( $\square$ ), Cell growth (optical density, $600 \mathrm{~nm}$ ); ( $\mathbf{\square})$, GABA production (g/l).

(Fig. 2). Among the isolated strains, E. avium JS-N6B4 derived from $A$. dichotoma larvae showed maximum GABA production $(3.24 \mathrm{~g} / \mathrm{l})$, followed by the strain isolated from G. bimaculatus $(0.47 \mathrm{~g} / \mathrm{l})$. This difference may arise owing to the differences in expression levels and kinetic characteristics of GAD expressed in each GABA-producing strain. These differences affect the rate of bio-conversion of L-glutamate to GABA.

Due to the complex components in MRS broth, the effect of carbon sources on GABA production was investigated with a simplified basic medium $(10 \mathrm{~g} / 1$ yeast extract, $10 \mathrm{~g} / 1$ MSG, and $1 \mathrm{~g} / 1 \mathrm{~K}_{2} \mathrm{HPO}_{4}$ ) supplemented with $1 \%(\mathrm{w} / \mathrm{v})$ of different carbon sources. The carbon and nitrogen sources that yielded the highest GABA production were investigated. As shown in Fig. 3, the switch from modified MRS broth to basic medium resulted in a 2.08 -fold increase in GABA production (from 0.47 to $0.98 \mathrm{~g} / \mathrm{l}$ ) with $P$. sp. L-G7, 1.86fold increase (from 0.33 to $0.60 \mathrm{~g} / 1$ ) with E. avium No-22-1, 10.11-fold increase (from 0.23 to $2.32 \mathrm{~g} / \mathrm{l}$ ) with E. avium $\mathrm{HJ}$ $\mathrm{N6}$, and 1.98-fold increase (from 3.24 to $6.40 \mathrm{~g} / \mathrm{l}$ ) with E. avium JS-N6B4. Overall, each strain showed an increase in GABA production in response to the change in the medium composition from MRS broth to basic medium. Medium components such as carbon and nitrogen sources exert a strong influence on GABA production [26].
Therefore, GABA production could be improved by the optimization of carbon and nitrogen sources for each strain. Here, carbon and nitrogen sources for optimum GABA production by the four species described herein

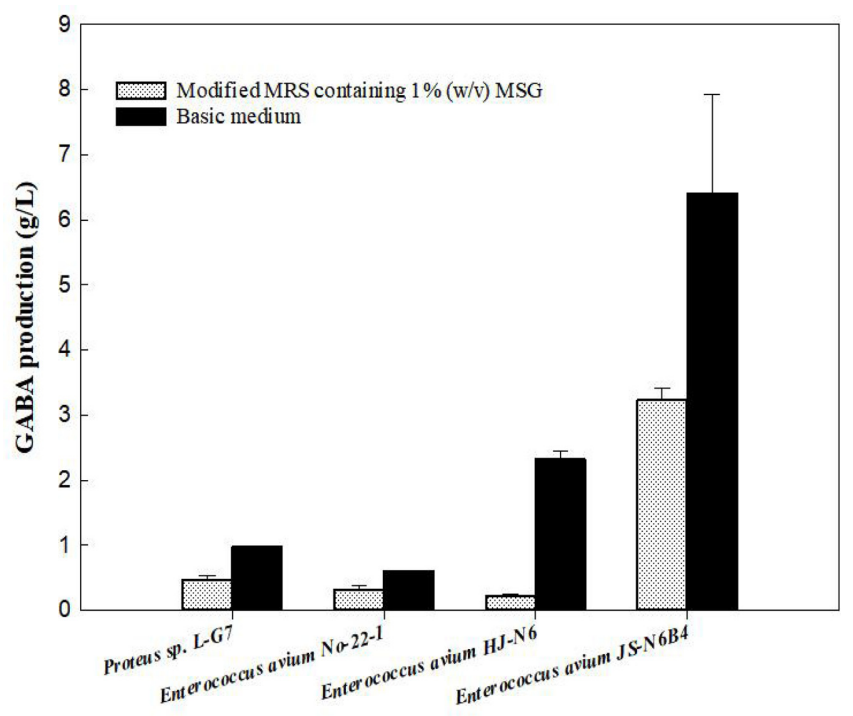

Fig. 3. Improvement in GABA production through the optimization of carbon and nitrogen sources for the growth of edible insect-derived strains in culture media. 

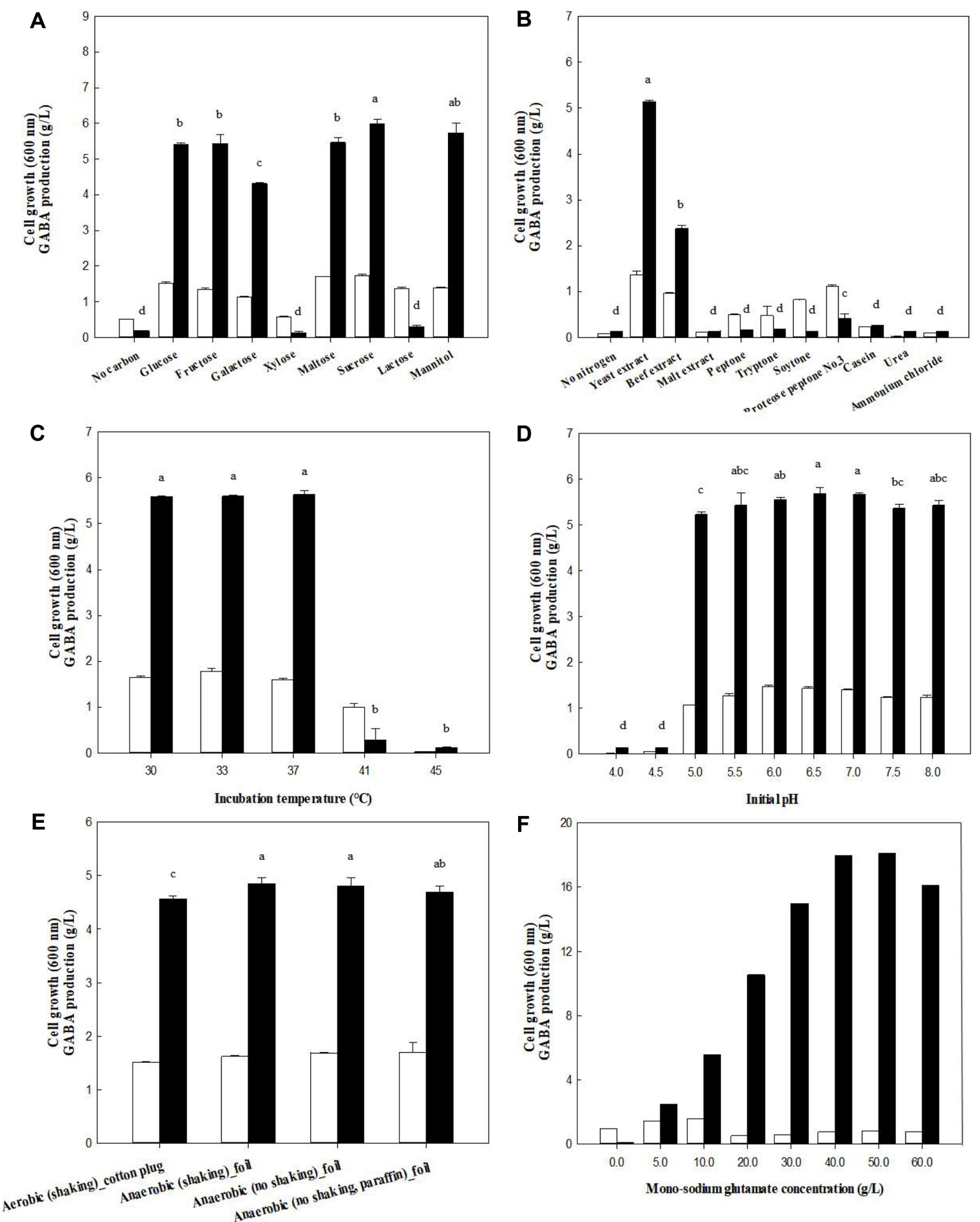

Fig. 4. Effect of carbon sources (A), nitrogen sources (B), incubation temperature (C), initial pH (D), aerobic culture and anaerobic culture (E), and mono-sodium glutamate concentrations (F) on the growth and GABA production of E. avium JS-N6B4. $(\square)$, Cell growth (optical density, $600 \mathrm{~nm}$ ); ( $\mathbf{\square})$, GABA production (g/l).

were determined. E. avium JS-N6B4 was selected as the best GABA-producing bacterium strain for further experiments.
Effect of Culture Conditions on GABA Production

The effects of various carbon sources on GABA production 
by E. avium JS-N6B4 were investigated in basic medium. As shown in Fig. 4A, carbon sources influenced both the growth and GABA production of E. avium JS-N6B4. Among the tested carbon sources, glucose served as an economical and cheap source and proved as the optimal carbon source for this strain. The effects of nitrogen sources on GABA production were evaluated using $10 \mathrm{~g} / 1$ glucose as the carbon source. Among the tested nitrogen sources (Fig. 4B), yeast extract resulted in the highest GABA level $(5.14 \mathrm{~g} / \mathrm{l})$, followed by beef extract $(2.38 \mathrm{~g} / \mathrm{l})$. The change in the optimum nitrogen and carbon sources resulted in minor differences in the amount of GABA produced by E. avium JS-N6B4, as evident from the production level of $(5.14 \mathrm{~g} / 1$ with glucose-yeast extract) and (5.14 g/1 with sucrose-beef extract). Although there would be various factors in GABA production, we could not accurately interpret the effects of each ingredient from the mixed nitrogen sources. Finally, GABA production by E. avium JS-N6B4 was carried out in the presence of glucose and yeast extract as carbon or nitrogen source, respectively.

The effect of culture temperature on GABA production by E. avium JS-N6B4 was investigated in basic medium. As shown in Fig. $4 \mathrm{C}$, GABA production was maximum at $37^{\circ} \mathrm{C}$ $(5.63 \mathrm{~g} / \mathrm{l})$, followed by $33^{\circ} \mathrm{C}(5.60 \mathrm{~g} / \mathrm{l})$. However, a similar level of production was achieved at temperatures of $33^{\circ} \mathrm{C}-$ $37^{\circ} \mathrm{C}$. GABA production significantly decreased at $41^{\circ} \mathrm{C}$ or higher owing to cell growth inhibition. Culture temperature is a major factor affecting GABA production depending on the expression or catalytic activity of GAD. Therefore, high cell density and appropriate culture temperature are essential for the efficient conversion of glutamate to GABA [27]. From the above results, we concluded that the growth and GABA production of E. avium JS-N6B4 were stable at $33^{\circ} \mathrm{C}-37^{\circ} \mathrm{C}$. We selected $37^{\circ} \mathrm{C}$ as the optimum temperature. We tested the effect of initial $\mathrm{pH}$ on the GABA production ability of E. avium JS-N6B4 (Fig. 4D), and found better GABA production at $\mathrm{pH}$ values from $6.5(5.69 \mathrm{~g} / 1)$ to 7.0 $(5.67 \mathrm{~g} / 1)$. Therefore, the initial $\mathrm{pH}$ was not adjusted for basic medium in subsequent experiments. The effects of
Table 2. Effect of various initial MSG concentrations and feeding regimens on GABA production by E. avium JS-N6B4 using basic medium.

\begin{tabular}{|c|c|c|c|c|c|}
\hline \multicolumn{4}{|c|}{ MSG (g/l) } & \multirow{3}{*}{$\begin{array}{l}\text { Optical density } \\
(600 \mathrm{~nm})\end{array}$} & \multirow{3}{*}{$\begin{array}{c}\text { GABA } \\
\text { production } \\
(\mathrm{g} / \mathrm{l})\end{array}$} \\
\hline \multirow{2}{*}{ Initial } & \multicolumn{3}{|c|}{ Feeding } & & \\
\hline & $24 \mathrm{~h}$ & $48 \mathrm{~h}$ & $72 \mathrm{~h}$ & & \\
\hline 40 & & & & $1.14 \pm 0.05$ & $12.47 \pm 0.29$ \\
\hline 10 & 10 & 10 & 10 & $1.16 \pm 0.03$ & $10.15 \pm 0.44$ \\
\hline 100 & & & & $0.66 \pm 0.01$ & $4.02 \pm 0.63$ \\
\hline 40 & 20 & 20 & 20 & $0.84 \pm 0.01$ & $11.02 \pm 0.95$ \\
\hline
\end{tabular}

aerobic and anaerobic conditions on GABA production by E. avium JS-N6B4 were investigated in basic medium. No statistically significant difference in cell growth and GABA production was observed between aerobic and anaerobic cultures. GABA production was slightly better in shaking cultures $(4.85 \mathrm{~g} / \mathrm{l})$ than in non-shaking cultures $(4.80 \mathrm{~g} / \mathrm{l})$ blocked with foil (Fig. 4E). Furthermore, GABA production in aerobic cultures $(4.69 \mathrm{~g} / \mathrm{l})$ was slightly higher than that in anaerobic cultures $(4.57 \mathrm{~g} / \mathrm{l})$.

The effects of MSG concentration and feeding regimens on GABA production of E. avium JS-N6B4 were investigated in basic medium. At $40 \mathrm{~g} / 1 \mathrm{MSG}$ concentration, batch supply resulted in more effective GABA production $(12.47 \mathrm{~g} / \mathrm{l})$, than fed-batch supply (10.15 g/l). At $100 \mathrm{~g} / 1 \mathrm{MSG}$ concentration, the cell growth was significantly inhibited with both feeding types, and GABA production was affected. These results suggest that E. avium JS-N6B4 restricts high initial MSG concentration, which may directly induce toxic effects such as apoptosis [28]. As shown in Table 2 and Fig. 4F, 40-50 g/l of MSG was chosen as the suitable concentration range for GABA production to avoid growth inhibition of E. avium JS-N6B4. GABA production has been previously carried out using a two-stage fermentation strategy, wherein maximum biomass production was achieved in the first stage and biotransformation of MSG into GABA was achieved in the second stage [29].

Table 3. Analysis of variance for the response surface methodology parameters fitted to a second-order polynomial equation.

\begin{tabular}{lcccc}
\hline \multicolumn{1}{c}{ Source } & Sum of square & Degree of freedom & Mean square & $F$-value \\
\hline Regression model & 355.098 & 9 & 39.455 & 22.172 \\
Residual & 17.795 & 10 & 1.780 & $<0.0001$ \\
Lack of fit & 15.437 & 5 & 3.087 & 0.0294 \\
Pure error & 2.359 & 5 & 0.472 & \\
Corrected total & 372.893 & 19 & & \\
\hline
\end{tabular}

$R^{2}=0.952 ; C V=15.068 \% ;$ Adjusted $-R^{2}=0.909 ;$ Predicted $-R^{2}=0.669$ 


\section{Optimization of GABA Production Based on RSM}

GABA production of E. avium JS-N6B4 was optimized based on medium composition to increase the economic availability. To determine the optimum concentrations of the combination of key variables such as glucose, yeast extract, and MSG, a second-order polynomial equation was fitted to the responses (Table 1). Results of the ANOVA of the second-order response surface model fitting are shown
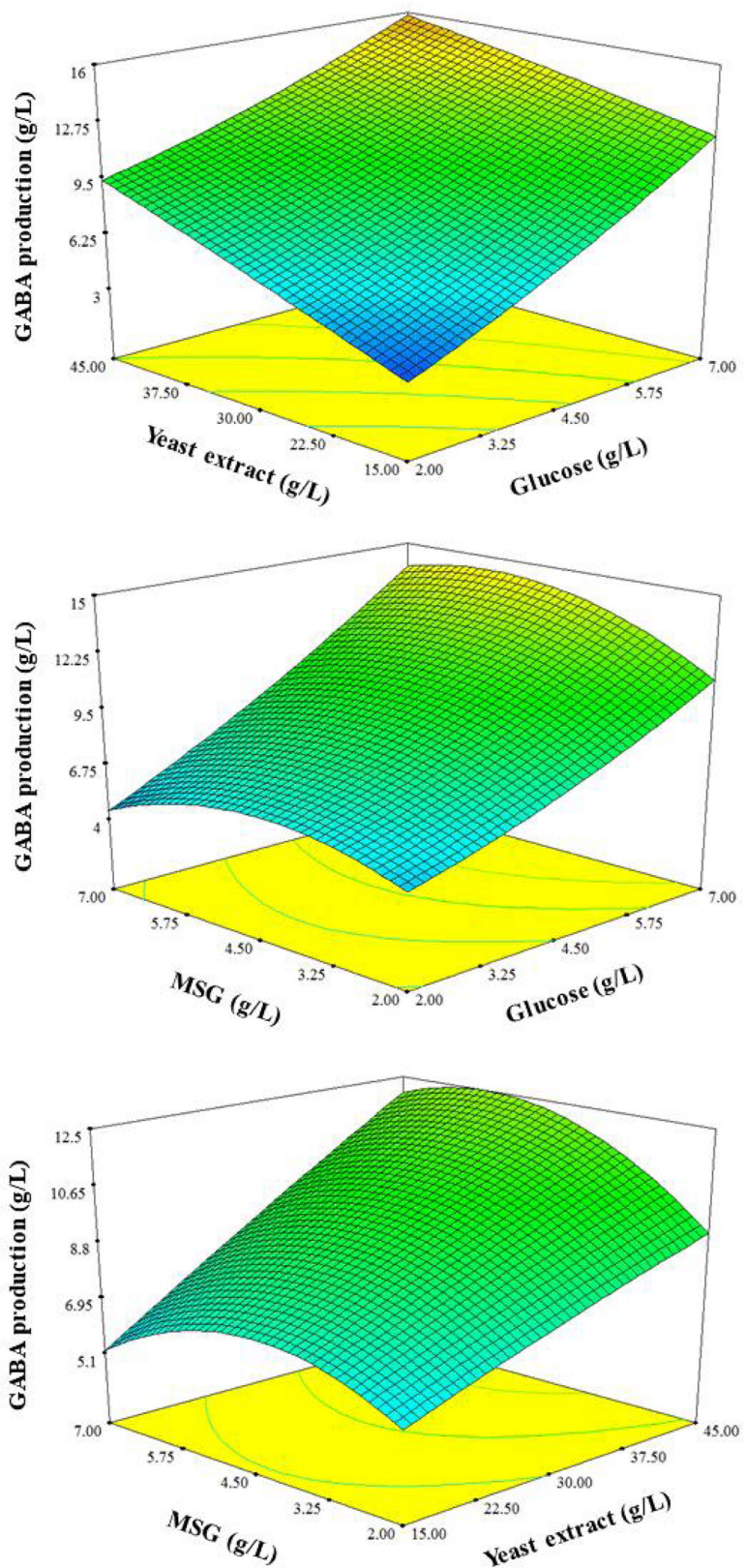

Fig. 5. Three-dimensional response surface plots for GABA production showing the interactive effects of glucose, yeast extract, and MSG concentration. in Table 3. To test the quality of the model, the regression equation and coefficient of determination $\left(R^{2}\right)$ were evaluated. The model presented a high coefficient of determination $\left(R^{2}=0.95\right)$, explaining $95 \%$ variability in the response. The adjusted coefficient of determination was also high, indicative of the strong significance of the model. The coefficients of the regression equation were calculated using Design-Expert statistical package software, and the following regression equation was obtained.

$$
\begin{aligned}
& y(\mathrm{GABA})=9.748273+3.834204 A+2.566301 B+0.586154 C \\
- & 0.63138 A B+0.8585 A C+0.8275 B C+0.459972 A^{2}-0.11614 B^{2} \\
- & 1.65463 C^{2}
\end{aligned}
$$

where $A, B$, and $C$ are glucose $(\mathrm{g} / \mathrm{l})$, yeast extract $(\mathrm{g} / \mathrm{l})$ and MSG (\%-w/v) concentrations, respectively.

The three-dimensional response surface plots are graphical representations of the regression equation. The main objective of response surface analysis was to efficiently determine the optimum values of variables in combination to maximize the response. The response surface and contour plots obtained in this study are presented in Fig. 5. The optimized values of each parameter to maximize GABA production were obtained by regression. The optimum concentrations of each variable according to this analysis were as follows: glucose $(A)=7 \mathrm{~g} / \mathrm{l}$, yeast extract $(B)=45 \mathrm{~g} / \mathrm{l}$, MSG $(C)=6.21 \%(\mathrm{w} / \mathrm{v})$. The predicted GABA production level under these optimized conditions was $16.64 \mathrm{~g} / 1$. The predicted optimum levels were tested in a

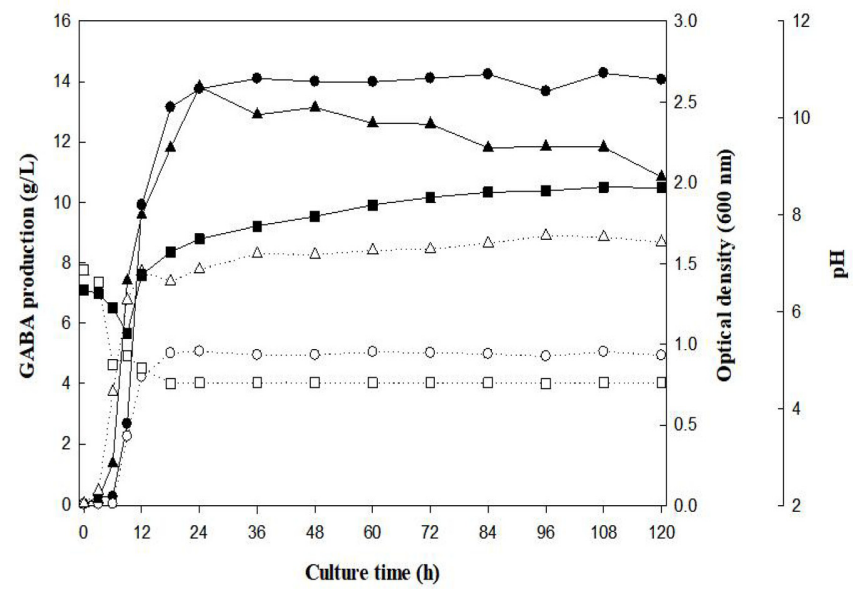

Fig. 6. GABA production, $\mathrm{pH}$, and growth curve of E. avium JS-N6B4 under optimized and basic medium.

-, GABA production on optimized medium; $\bigcirc$, GABA production on basic medium; $\triangle$, cell growth on optimized medium; $\triangle$, cell growth on basic medium; $\mathbf{\square}$, pH of the optimized medium; $\square, \mathrm{pH}$ of the basic medium. 
flask-scale experiment incorporating all other optimized conditions to assess the adequacy of this quadratic model in predicting GABA production. As shown in Fig. 6, maximum GABA concentration was $13.68 \mathrm{~g} / \mathrm{l}$, which was closely related to the predicted value $(16.64 \mathrm{~g} / \mathrm{l})$. This result indicates that the regression model developed in this study shows good agreement between actual and predicted responses. After medium optimization with RSM, GABA production of E. avium JS-N6B4 increased by 2.79 -fold $(13.68 \mathrm{~g} / \mathrm{l})$ compared with the $4.90 \mathrm{~g} / 1$ level obtained with basic medium. Cells entered stationary phase after $24 \mathrm{~h}$ and GABA production failed to increase owing to the absence of cell growth. Therefore, to promote GABA production, feeding glucose after $24 \mathrm{~h}$ is essential to induce cell growth. Furthermore, the $\mathrm{pH}$ of the medium increased over time, making it unfavorable for the microbial production of GABA. Proper acidification of the culture medium is needed for the conversion of glutamate to GABA [29]. It is necessary to continuously adjust the $\mathrm{pH}$ to promote GABA production.

In conclusion, a GABA producing-bacterium, E, avium JSN6B4G, was successfully isolated from an edible insect, $A$ dichotoma, and its culture medium was optimized for GABA production using RSM. The optimized cultivation method resulted in a 2.79-fold increase in GABA levels as compared with the basic medium. The GABA-producing strain may expand the industrial value of edible insects as protein alternatives or functional pharmaceutical biomaterials. Although Enterococcus avium was isolated from fermented sea food [12, 29] or human intestine [30], E. avium is most commonly isolated from the gastro intestinal and urinary tracts [31]. For application in various areas, current research is focused on the genomic approach and bacterial safety.

\section{Acknowledgments}

This research was supported by the Basic Science Research Program through the National Research Foundation of Korea (NRF) funded by the Ministry of Education (NRF 2019R1F1A1058385) and carried out with the support of "Cooperative Research Program for Agriculture Science and Technology Development (Project No. PJ01256503)" Rural Development Administration, Republic of Korea.

\section{Conflict of Interest}

The authors have no financial conflicts of interest to declare.

\section{References}

1. Manyam BV, Katz L, Hare TA, Kaniefski K, Tremblay RD. 1981. Isoniazid-induced elevation of CSF GABA levels and effects on chorea in Huntington's disease. Ann. Neurol. 10: 35-37.

2. Lim HS, Cha IT, Lee HJ, Seo MJ. 2016. Optimization of $\gamma$-aminobutyric acid production by Enterococcus faecium JK29 isolated from a traditional fermented foods. Microbiol. Biotechnol. Lett. 44: 26-33.

3. Tajabadi N, Ebrahimpour A, Baradaran A, Rahim RA, Mahyudin NA, Manap MY, et al. 2015. Optimization of $\gamma$-aminobutyric acid production by Lactobacillus plantarum Taj-Apis362 from honeybees. Molecules 20: 6654-6669.

4. Wong CG, Bottiglieri T, Snead OC 3rd. 2003. GABA, $\gamma$-hydroxybutyric acid, and neurological disease. Ann. Neurol. 54: S3-S12.

5. Inoue K, Shirai T, Ochial H, Kasao M, Hayakawa K, Kimura M, et al. 2003. Blood-pressure-lowering effect of a novel fermented milk containing $\gamma$-aminobutyric acid (GABA) in mild hypertensives. Eur. J. Clin. Nutr. 57: 490-495.

6. Jakobs C, Jaeken J, Gibson KM. 1993. Inherited disorders of GABA metabolism. J. Inherit. Metab. Dis. 16: 704-715.

7. Barragan A, Weidner JM, Jin Z, Korpi ER, Birnir B. 2015. GABAergic signaling in the immune system. Acta Physiol. 213: 819-827.

8. Seikuse T, Horino T, Mori Y. 1994. Accumulation of $\gamma$-aminobutyric acid (Gaba) in the rice germ during water soaking. Biosci. Biotechnol. Biochem. 58: 2291-2292.

9. Pliner P, Salvy SJ. 2006. Food neophobia in human, pp. 75-92. In Shepherd R, Raats M (eds.), The Psychology of Food Choice. Oxfordshire, CABI Publishing.

10. Huis A van, Itterbeeck JV, Llunder H, Mertens E, Halloran A, Muir G, et al. 2013. Edible insects: future prospects for food and feed security. Rome: Food and Agriculture Organization of the United Nations (FAO forestry paper 171). ISBN 9789251075968-187. Available from http://www.fao.org/3/ i3253e/i3253e.pdf. Accessed Apr. 28, 2019.

11. Lim HS, Cha IT, Rh SW, Shin HH, Seo MJ. 2017. Enhanced production of gamma-aminobutyric acid by optimizing culture conditions of Lactobacillus brevis HYE1 isolated from kimchi, a Korean fermented food. J. Microbiol. Biotechnol. 27: 450-459.

12. Lee KW, Shim JM, Yan Z, Kim JA, Kim JH. 2018. Properties of kimchi fermented with GABA-producing lactic acid bacteria as a starter. J. Microbiol. Biotechnol. 28: 209-221.

13. Lee HJ, Son JY, Lee SJ, Lee HS, Kee BJ, Choi IS, et al. 2017. Production of gamma-aminobutyric acid (GABA) by Lactobacillus plantarum subsp. plantarum B-134 isolated from Makgeolli, traditional Korean rice wine. J. Life Sci. 27: 567-574.

14. Vo T, Park JH. 2019. Characteristics of potential gammaaminobutyric acid-producing bacteria isolated from Korean 
and Vietnamese fermented fish products. J. Microbiol. Biotechnol. 29: 209-221.

15. Nomura M, Kimoto H, Someya Y, Furukawa S, Suzuki I. 1998. Production of gamma-aminobutyric acid by cheese starters during cheese ripening. J. Dairy Sci. 81: 1486-1491.

16. Park KB, Oh SH. 2007. Production of yogurt with enhanced levels of gamma-aminobutyric acid and valuable nutrients using lactic acid bacteria and germinated soybean extract. Bioresour. Technol. 98: 1675-1679.

17. Siragusa S, De Angelis M, Di Cagno R, Rizzello CG, Coda R, Gobbetti M. 2007. Synthesis of c-aminobutyric acid by lactic acid bacteria isolated from a variety of Italian cheeses. Appl. Environ. Microbiol. 73: 7283-7290.

18. Rizzello CG, Cassone A, Di Cagno R, Gobbetti M. 2008. Synthesis of angiotensin I-converting enzyme (ACE)-inhibitory peptides and gamma-aminobutyric acid (GABA) during sourdough fermentation by selected lactic acid bacteria. J. Agric. Food Chem. 56: 6936-6943.

19. Li H, Cao Y, Gao D, Xu H. 2008. A high c-aminobutyric acid producing ability Lactobacillus brevis isolated from Chinese traditional paocai. Ann. Microbiol. 58: 649-653.

20. Thompson JD, Gibson TJ, Plewniak F, Jeanmougin F, Higgins DG. 1997. The CLUSTAL_X window interface: flexible strategies for multiple sequence alignment aided by quality analysis tools. Nucleic Acids Res. 25: 4876-4882.

21. Li H, Qui T, Cao Y, Yang J, Huang Z. 2009. Pre-staining paper chromatography method for quantification of $\gamma$-aminobutyric acid. J. Choromatogr. A. 1216: 5057-5060.

22. Su D, Robyt JF. 1993. Control of the synthesis of dextran and acceptor-products by Leuconostoc mesenteroides B-512FM dextransucrase. Carbohydr. Res. 248: 339-348.
23. Rossetti V, Lombard A. 1996. Determination of glutamate decarboxylase by high-performance liquid chromatography. J. Chromatogr. B. Biomed. Appl. 681: 63-67.

24. Li H, Cao Y. 2010. Lactic acid bacterial cell factories for gamma-aminobutyric acid. Amino Acids 39: 1107-1116.

25. Kook MC, Cho SC. 2013. Production of GABA (gamma amino butyric acid) by lactic acid bacteria. Korean J. Food Sci. An. 33: 377-389.

26. Wang JJ, Lee CL, Pan TM. 2003. Improvement of monacolin $\mathrm{K}$, c-aminobutyric acid and citrinin production ratio as a function of environmental conditions of Monascus purpureus NTU 601. J. Ind. Microbiol. Biotechnol. 30: 669-676.

27. Kim JY, Lee MY, Ji GE, Lee YS, Hwang KT. 2009. Production of $\gamma$-aminobutyric acid in black raspberry juice during fermentation by Lactobacillus brevis GABA 100. Int. J. Food Microbiol. 130: 12-16.

28. Moldzio R, Radad K, Krewenka C, Kranner B, Duvigneau JC, Rausch WD. 2013. Protective effects of resveratrol on glutamate-induced damages in murine brain cultures. J. Neural. Transm (Vienna). 120: 1271-1280.

29. Yang H, Xing R, Hu L, Liu S, Li P. 2016. Accumulation of $\gamma$-aminobutyric acid by Enterococcus avium 9184 in scallop solution in a two-stage fermentation strategy. Microb. Biotechnol. 9: 478-485.

30. Shin NR, Moon JS, Shin SY, Li L, Lee YB, Kim TJ, et al. 2015. Isolation and characterization of human intestinal Enterococcus avium EFEL009 converting rutin to quercetin. Lett. Appl. Microbiol. 62: 68-74.

31. Gonzales RD, Schreckenberger PC, Graham MB, Kelkar S, DenBesten K, Quinn JP. 2001. Infections due to vancomycinresistant Enterococcus faecium resistant to linezolid. Lancet 357: 1179. 